\title{
Endocrine disruptive chemicals: mechanisms of action and involvement in metabolic disorders
}

\author{
Elin Swedenborg*, Joëlle Rüegg*, Sari Mäkelä1 and Ingemar Pongratz \\ Department for Biosciences and Nutrition, Karolinska Institute at Novum, S-14157 Huddinge, Sweden and ${ }^{1}$ Functional Foods Forum and Department of Biochemistry and Food \\ Chemistry, University of Turku, FI-20014 Turku, Finland \\ (Correspondence should be addressed to J Rüegg; Email: joerue @ki.se) \\ *(These authors contributed equally to this work)
}

\begin{abstract}
Endocrine disruption refers to the ability of chemicals to interfere with hormonal systems, and has raised considerable concern in recent years. Endocrine disruptive chemicals (EDCs) pose a documented risk to wildlife and have the potential to negatively influence human health. This review focuses on the molecular mechanisms of endocrine disruption and the possible involvement of EDCs in metabolic disorders. The first part describes the role of aryl hydrocarbon receptor (AhR) and nuclear receptors (NRs) in mediating effects of EDCs, in particular, how cross-talk between AhR and NR pathways can lead to endocrine disruption. The second part deals with how these receptors are involved in metabolic functions and how their targeting by EDCs can lead to disturbances in glucose and fat metabolism. The article illustrates that, although there is accumulating data on molecular mechanisms of EDC action as well as on EDC involvement in metabolic disorders, there is still a great demand for data that can unite the mechanistic and the toxicological /epidemiological observations.
\end{abstract}

Journal of Molecular Endocrinology (2009) 43, 1-10

\section{Introduction}

With industrialization, the production of chemicals and their introduction into the environment has increased massively. Some of these chemicals act as endocrine disruptors as they disturb endogenous hormone signaling pathways. Epidemiological studies suggest an association between the increasing exposure to chemicals and the development of some of the main ailments of the industrialized world e.g., disturbances in reproduction, hormone-related cancers, and metabolic disorders like obesity and diabetes type 2 . However, this association is still debated and the possible molecular mechanisms underlying endocrine disruption and disease development are far from understood.

To date, most studies have focused on the effects that endocrine disruptive chemicals (EDCs) pose on reproductive processes regulated by hormonal signaling mediated by members of the family of nuclear receptors (NRs), in particular the estrogen receptors (ERs) and the androgen receptor. In addition, the thyroid hormone receptors, and more recently, retinoid $\mathrm{X}$ receptor (RXR), and peroxisome proliferator-activated receptors (PPARs) are shown to be targets for EDC action. EDCs can affect these systems in several different ways for example by directly interfering with receptor signaling or by activating other signaling pathways, in particular that of the aryl hydrocarbon receptor (AhR), a receptor involved in the metabolism of many xenobiotic substances.

This review focuses on the molecular mechanisms by which EDCs can affect NR signaling without direct binding to the receptors. In addition, the consequences of endocrine disruption for human health are discussed, in particular possible involvement of EDC exposure on the development of metabolic diseases.

\section{Mechanistic aspects of endocrine disruption}

The interference exerted by an exogenous substance with the hormonal system is referred to as endocrine disruption and the substances themselves are known as endocrine disrupting chemicals (EDCs). Although EDCs can affect every possible cellular hormonal pathway, most information is available about 
interference of EDCs with the hormone receptors of the nuclear receptor family. The NRs represent a family of structurally related transcription factors (reviewed in Gronemeyer et al. (2004)). In mammals, 48 NRs have been identified which are involved in virtually all vital functions, e.g., fetal development, homeostasis, reproduction, metabolism, and response to xenobiotic substances. The hormone receptors of this family are the steroid hormone receptors ERs, androgen receptor (AR), progesterone receptor (PR), glucocorticoid receptor (GR), and mineralocorticoid receptor as well as the thyroid hormone receptors (TRs). Some EDCs can bind directly to these receptors either as agonists or antagonists, thus enhancing or inhibiting the effect of a hormone, respectively. However, there are other mechanisms of EDC action described, in particular with involvement of the AhR. The AhR is a ligandactivated transcription factor and a key regulator of the cellular response to xenobiotic exposure. It belongs to the family of the bHLH-PAS proteins, and is ubiquitously expressed and well conserved throughout evolution. It is strongly activated by organic compounds such as polychlorinated dibenzodioxins (commonly referred to as dioxin), dibenzofurans (PCDF), biphenyls (PCB) as well as polycyclic aromatic hydrocarbons (PAHs) like 3-methylcholanthrene (3-MC), benzo[a]pyrene (BaP) and benzoflavone (Poland \& Knutson 1982). In addition, a number of natural and endogenous compounds have been identified as AhR activators.

Transcriptional activation of $A h R$ and NRs are very similar (Fig. 1; reviewed in Rüegg et al. (2008)). In the absence of ligand, the receptors reside either in the cytoplasm or in the cell nucleus in a complex with chaperones and/or co-repressors (Petrulis \& Perdew 2002, Picard 2006). Ligand binding triggers conformational changes that lead to dissociation of the repressive complex, the recruitment of transcriptional co-activators, and receptor dimerization (Lee et al. 2001, Hankinson 2005). NRs either homodimerize or heterodimerize with RXR, whereas AhR dimerizes with its obligatory partner AhR nuclear translocator $(\mathrm{ARNT})$. This finally leads to gene transcription of NR or AhR target genes (Swanson 2002, Claessens \& Gewirth 2004). Alternatively, some NRs like the TRs are constantly bound to their recognition sites on the DNA (Fig. 1C). In the absence of ligand, they are found in a complex with transcriptional co-repressors, thus repressing target gene expression. Ligand binding triggers exchange of these co-repressors with co-activators, which in turn leads to transcriptional activation (Wu \& Koenig 2000).

As direct binding to hormone receptors is by far the most studied mechanism of endocrine disruption and covered in the literature (reviewed in Janosek et al. (2006) and Rüegg et al. (2008)), the following sections
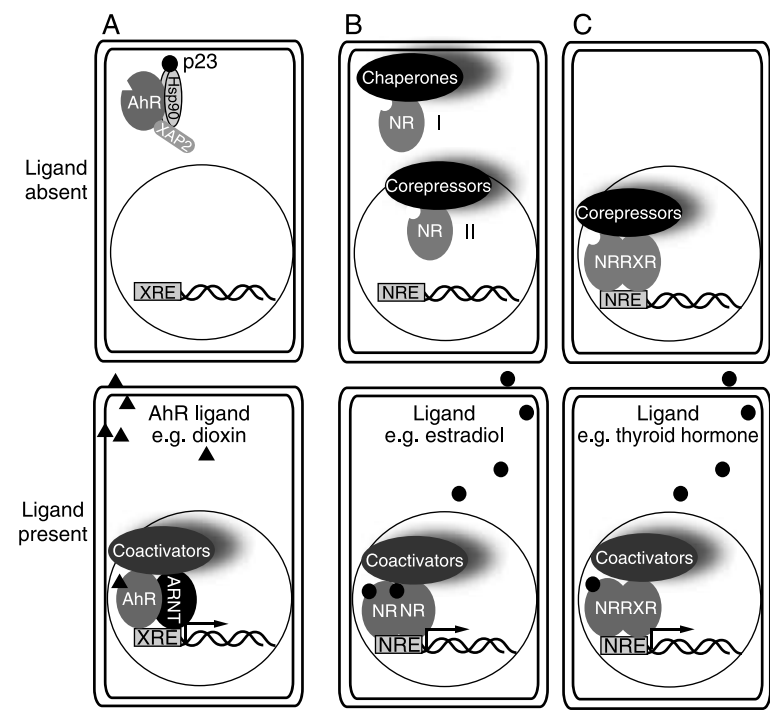

Figure 1 Signaling pathways of AhR and NRs. (A) In the absence of ligand, AhR is located in the cytoplasm in a complex with chaperones and co-chaperones. Upon ligand binding, AhR translocates to the nucleus where it forms a complex with ARNT and co-activators, binds to xenobiotic response elements (XREs) on the DNA, and induces transcription of target genes. (B) In the absence of ligand, NRs reside either in the cytoplasm (I, e.g. glucocorticoid receptor) or in the nucleus (II, e.g. estrogen receptors), bound to chaperones and/or co-repressors. Ligand binding induces nuclear translocation and/or exchange of co-repressors to co-activators, binding to NR response elements (NREs), and gene transcription. (C) Some NRs like the thyroid receptors are bound to the DNA even in the absence of ligand, thereby repressing target gene expression. Ligand binding results in co-activator recruitment and subsequent activation of these genes.

provide examples of recently described mechanisms that are based on the cross-talk between NR and AhR signaling (summarized in Fig. 2).

\section{Interference with hormone receptor activity through direct protein degradation}

Targeted degradation via the ubiquitin-proteasome pathway is one way by which the levels of nuclear hormone receptors are regulated. Recent findings indicate that both $\mathrm{AhR}$ and its heterodimerization partner ARNT are a part of cullin 4B ubiquitin ligase, a multi-protein complex involved in targeting proteins to the proteasome. Additionally, the assembly of this complex seems to be AhR liganddependent (Ohtake et al. 2007), suggesting that AhR ligands can interfere with hormonal signaling by targeting hormone receptors to the proteasome. This observation is supported by earlier findings where some AhR ligands with anti-estrogenic properties could decrease $\mathrm{ER} \alpha$ levels by proteasomal degradation (Wang et al. 1993). 
A Direct interaction of EDC with NRs

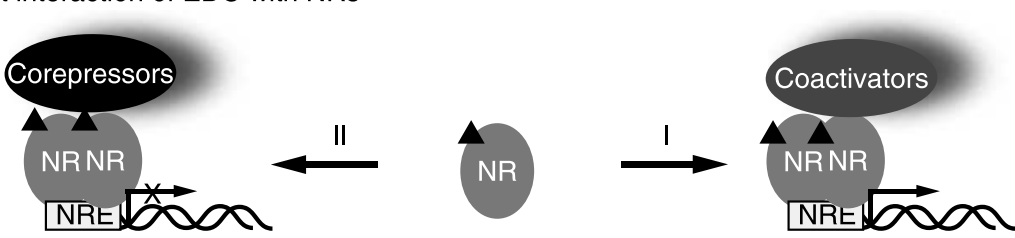

B Disturbance of NR signaling

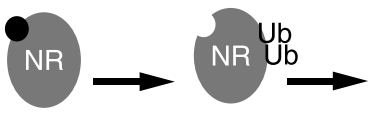

I: Changes in proteasomal degradation of the receptor

III: Inhibition of receptor activity by neighboring inhibitory XREs

C Changes in hormone availability

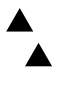

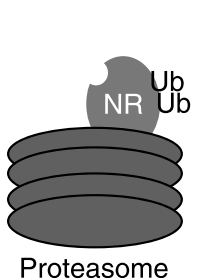

Proteasome

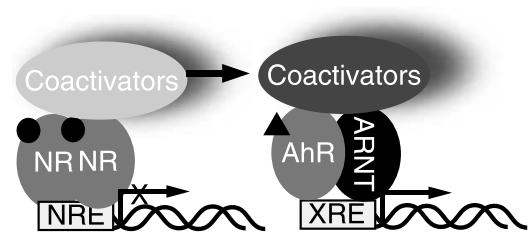

II: Competition between xenobiotic and hormonal signaling for coactivators or ARNT
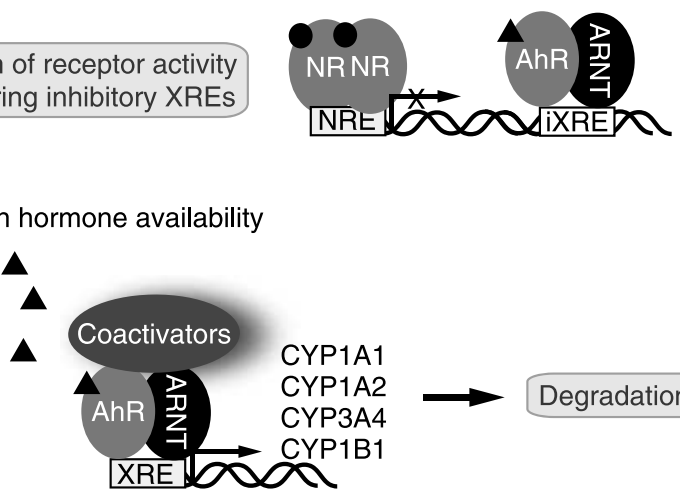

Figure 2 Mechanisms of endocrine disruption. (A) Many endocrine disruptive chemicals (EDCs) have similar structures to NR ligands and can directly bind to NRs. They can either act as agonists and induce gene expression (I) or function as antagonists and inhibit the activity of the receptor (II). (B) EDCs can affect receptor function by I: inducing receptor degradation, II: inducing e.g., the AhR signaling pathway, which in turn sequesters common co-activators and ARNT away from the NRs, and III: by associating with the AhR that can bind to inhibitory XREs close to NREs. (C) Enzymes induced by activated AhR are not only involved in metabolism of xenobiotics but also in the catabolism of e.g., steroid hormones. Thus, induction of these enzymes can lead to reduced availability of endogenous hormones.

\section{Interference with co-activator recruitment}

The activity of both NRs and the AhR is dependent on transcriptional co-activators. A number of these co-activators are shared by many of the NRs as well as the AhR. Thus, competition between e.g., the steroid hormone receptors and AhR for common co-activators is a plausible mechanism by which AhR ligands may disturb steroid hormone signaling. Indeed, overexpression of the co-activator-binding domain of AhR and of the ERs in mammalian cells leads to impaired activity of ER and AhR respectively (Reen et al. 2002), suggesting that there is competition between ER and AhR for common co-activators. In fact, competition between ER and AhR for ARNT has been shown to be at least partly responsible for the anti-estrogenic properties of the dioxin TCDD (Brunnberg et al. 2003, Rüegg et al. 2007). Although ARNT is not considered to be a classical transcriptional co-activator, it shares many properties with the SRC family of co-activators and has been shown to act as co-activator of the ERs (Brunnberg et al. 2003), in particular of ER $\beta$ (Rüegg et al. 2007). Competition for common co-activators occurs also within the NR family; it has been shown that activation of CAR, a NR involved in metabolism of xenobiotic substances, inhibits ER activity by reducing the available levels of the p160 co-activator GRIP-1 (Min et al. 2002).

\section{Interference on the DNA}

A complex interplay between AhR and ER has been demonstrated on certain promoters of ER target genes. Activated AhR can bind to sequences close to ER binding sites, so-called inhibitory (i) XREs, that have slightly different base composition than XREs, so that 
AhR can bind but cannot activate gene transcription (reviewed in Safe \& Wormke (2003)). On the other hand, unliganded AhR can bind to XREs close to ER binding sites in certain promoter regions, which in fact seems to be necessary for the transcriptional activation of the respective gene by ER (Hockings et al. 2006). Binding of liganded AhR to the same XRE, however, negatively interferes with gene induction by ER. The complexity of the AhR-ER interactions is further underlined by a study showing that AhR ligands such as 3-MC activates ER $\alpha$, thereby inducing estrogenic effects (Ohtake et al. 2003). A later study demonstrated that the ability of 3-MC to activate ER $\alpha$-dependent transcription requires biotransformation to metabolites with estrogenic activity. Interestingly, in cells where 3-MC was not metabolized, 3-MC acted as an antiestrogen in close analogy to dioxin (Swedenborg et al. 2008). Similar findings have been obtained with other AhR ligands such as BaP (Arcaro et al. 1999). Thus, the estrogenic effects of AhR ligands have to be further studied, taking into account the ability of cells to convert xenobiotics like 3-MC or BaP into estrogenic compounds.

\section{Dysregulation of hormone metabolism}

Hormone availability is dependent on hormone biosynthesis, transport of the hormone to the target tissue, levels of hormone binding proteins, and hormone catabolism. EDCs have been described to interfere with all of these processes (e.g., Baker et al. 1998, You et al. 2001, Boas et al. 2006). Steroid hormone catabolism is particularly affected by EDCs, since many of the xenobiotic-metabolizing enzymes are involved in both these processes. For example, the P450 enzymes CYP1A2, CYP3A4, CYP1A1, and CYP1B1, all main target genes of AhR, are responsible for the hydroxylation of $17-\beta$ estradiol (Tsuchiya et al. 2005). Enzyme activation upon exposure to xenobiotics can thus lead to increased hormone catabolism, and consequently, compromise hormone signaling. Conversely, recent experiments have shown that CYP19B (aromatase), which converts testosterone to estradiol is a direct AhR target gene. Thus, activation of AhR by EDCs can lead both to increased degradation of steroid hormones as well as to higher estradiol production.

\section{Is exposure to EDCs involved in develop- ment of metabolic disorders?}

Many studies on endocrine disruption and NRs have discussed reproductive effects and effects on the immune and nervous systems, and several excellent reviews are available on these topics (Singleton \& Khan
2003, Colborn 2004, Panzica et al. 2005, Vidaeff \& Sever 2005, Tabb \& Blumberg 2006). We focus here on the possible involvement of EDCs in the development of obesity and metabolic syndrome (MetS).

MetS, sometimes referred to as insulin resistance syndrome or syndrome $\mathrm{X}$ is a term for a combination of disorders that may include impaired glucose tolerance or insulin resistance, dyslipidemia, high blood pressure, and obesity (reviewed in Despres et al. (2008) and Phillips \& Prins (2008)). Key factors are abdominal obesity and insulin resistance, where normal insulin levels are insufficient to reduce circulating levels of glucose or triglycerides. The condition, once established, is notoriously difficult to treat and leads to serious health problems, in particular increased risk for diabetes and cardiovascular disease. The obesity epidemic in the Western world can, in large parts, be explained by our lifestyle, which includes a lack of exercise and over-intake of high-caloric food (Oken \& Gillman 2003). Additionally, there are genetic components for developing obesity. Lately, it has been hypothesized that exposure to endocrine disruptors, in utero and onwards, may play a role in the development of obesity and related diseases (Baillie-Hamilton 2002, Newbold et al. 2007b, 2008). The molecular mechanisms behind a possible involvement of EDCs, so called obesogens, in obesity are poorly understood. However, it is known that a number of NRs are crucially involved in fat metabolism and glucose uptake. Recent findings also implicate roles for AhR and ARNT in these processes. Thus, it is likely that mechanisms of endocrine disruption discussed above account at least partly for obesogenic effects of EDCs.

Summary of the epidemiological evidence on EDC involvement in the onset of obesity is beyond the scope of this review and is covered by others (Newbold et al. 2007a, Elobeid \& Allison 2008). The following sections will focus on how AhR and some NRs are involved in fat metabolism and regulation of glucose uptake, and how this can link EDC exposure to metabolic disorders (summarized in Fig. 3).

\section{The arylhydrocarbon receptor}

Studies have shown that the AhR is involved in the regulation of lipogenesis and glucose homeostasis (Thackaberry et al. 2003, Sato et al. 2008). In addition, dioxin exposure has been reported to increase the risk for diabetes type 2 (Fierens et al. 2003) and 23\% of AhR null female mice are diabetogenic (Thackaberry et al. 2003). Gunton et al (2005) introduced a novel, central player in diabetes type 2, namely ARNT, the heterodimerization partner of AhR. A comparison of gene expression microarrays with DNA from patients with diabetes type 2 to normal subjects demonstrated that loss of ARNT expression causes impaired insulin release 


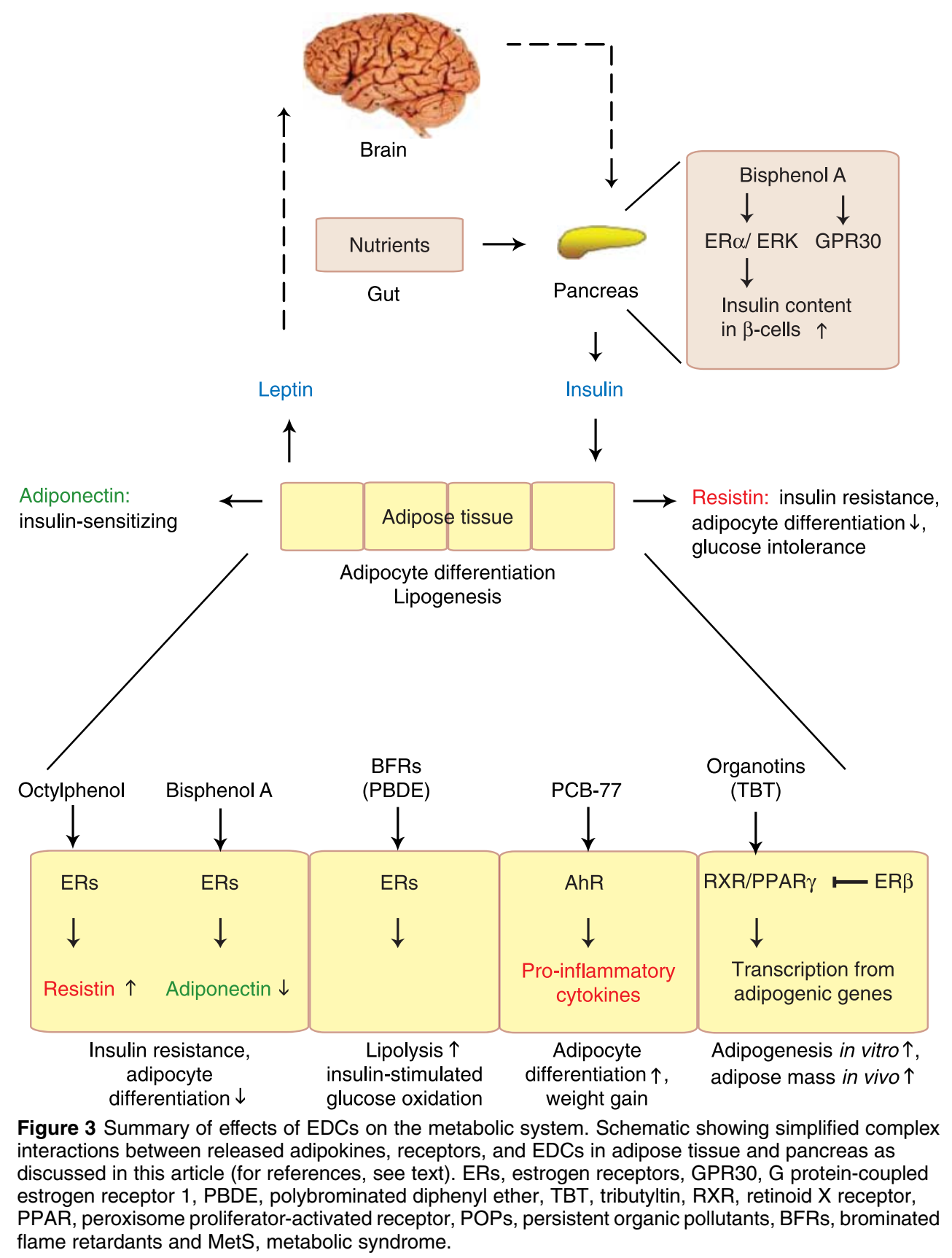

in human islets. Although it remains to be elucidated if abnormal ARNT expression is a cause or a consequence of diabetes type 2, it is likely that activation of AhR/ARNT by EDCs could interfere with the regulation of lipogenesis and glucose uptake. Indeed, persistent organic pollutants (POPs), a group of AhR ligands, have been found to be associated with both diabetes and MetS in an epidemiological study of human serum samples (Lee et al. 2006, 2007a,b,c).
Furthermore, it has recently been shown that lowdose exposure of co-planar PCB-77, so-called dioxinlike PCB, promotes adipocyte differentiation in an AhR-mediated way and triggers the release of proinflammatory adipokines from adipocytes. The authors conclude that low-dose exposure to PCB-77, which is accumulated in the adipose tissue, may contribute to the development of obesity and atherosclerosis (Arsenescu et al. 2008). 


\section{Estrogen receptors}

There is accumulating evidence that estrogen and its receptors play an important role in adipogenesis and adipose metabolism. In humans, the risk of developing obesity-related diseases is lower in pre- but not in postmenopausal women compared with men (Mattsson \& Olsson 2007). Studies in knock-out mice models have shown that the lack of $\mathrm{ER} \alpha$ as well as of estrogen itself leads to increased body weight and insulin resistance (Heine et al. 2000, Takeda et al. 2003).

Several exogenous estrogens have an impact on adipose tissue. One example is the environmental estrogenic compound octylphenol, a chemical widely used as surfactant and frequently found in wastewater (Bonefeld-Jorgensen et al. 2007). Octylphenol was demonstrated to upregulate resistin, an adipocytespecific hormone that may cause insulin-resistance and decrease adipocyte differentiation (Lee et al. 2008).

Another example are brominated flame retardants (BFRs) that have been reported to disrupt thyroid, androgen, and estrogenic signaling, both in vivo and in vitro (reviewed in Legler \& Brouwer (2003)), some of them by directly binding to the ERs (Meerts et al. 2001).

BFRs are a group of industrial chemicals produced in high quantities, mainly used in electric devices, textiles, and cars (for an extensive review see Darnerud 2003, 2008). These compounds are present in the environment at increasing levels and will be so for many years to come due to their environmental persistency. Most of the compounds are highly lipophilic and bioaccumulate in adipose tissue. Polybrominated diphenyl ether (PBDE) that is the dominating congener, has structural similarities to other environmental contaminants with endocrine disruptive effects, such as PCBs, and has been found in human serum, adipose tissue, and in breast milk samples (reviewed in Darnerud (2003)).

A recent screen of POPs and BFRs in human serum samples, showed a significant association with diabetes and MetS with 2 (PBB-153 and PBDE-153) out of six tested BFRs (Lim et al. 2008). The investigators conclude that brominated POPs stored in adipose tissue, may be involved in the pathogenesis of diabetes and MetS. In rats, exposure to penta-BDE in vivo for at least 4 weeks increased lipolysis and decreased glucose oxidation, both symptoms characteristic of diabetes and obesity (Hoppe \& Carey 2007).

Yet another example is bisphenol A (BPA), a monomer with strong estrogenic properties, used in its polymeric form as lining of food and beverage containers, baby bottles, medical tubing, and dental fillings. BPA has been shown to leak out from the plastic, both when heated and in room temperature (Howdeshell et al. 2003, Le et al. 2008), and human exposure is considered substantial (Vandenberg et al. 2007). It is a lipophilic compound and can accumulate in fat; it is also found in human plasma, urine, and breast milk (reviewed in Welshons et al. (2006)). A major controversy remains regarding the degradation of BPA in biological systems, and the impact this process has on the exposure levels.

The scientific evidence regarding the actual influence of xenobiotic exposure and human health has long been scarce. But, a recent epidemiological report by Lang et al. (2008), described a link between high urinary levels of BPA and cardiovascular disease, liver abnormalities, and diabetes in a US adult population. This cross-sectional study shows, for the first time, a clear correlation between high BPA exposure and disease in humans.

In addition, environmentally relevant doses of BPA were lately shown to significantly inhibit the release of adiponectin from adipocytes and human explants (Hugo 2008). Adiponectin is a key adipokine in the protection of human cells from metabolic syndrome, and these in vitro data corroborate the epidemiological report by Lang $e t$ al.

In another study, BPA administered at physiologically relevant doses was found to increase pancreatic $\beta$-cell insulin content. This seems to be ER $\alpha$-dependent, and involves signaling through a non-genomic pathway via extracellular regulated kinase1/2 (Alonso-Magdalena et al. 2008).

Although the main mediators of estrogen action are the ERs, there are other means by which estrogen signaling is transmitted. In particular, the non-classical ER GPR30 has recently been demonstrated to be crucially involved in the effects of estrogens on metabolism (Martensson et al. 2008). GPR30 is membrane-bound and belongs to the G-protein coupled class of receptors (reviewed in Prossnitz et al. (2008)). GPR30 deficient mice suffer from hyperglycemia, impaired glucose tolerance, and elevated blood pressure among other symptoms (Martensson et al. 2008). Interestingly, it has been shown that GPR30, like the classical ERs, are bound and activated by several EDCs, e.g. BPA (Thomas et al. 2005, Thomas \& Dong 2006). As GPR30 is expressed in pancreatic islets (Martensson et al. 2008), it could partly contribute to the increase of insulin after BPA exposure.

\section{Retinoid X receptor/peroxisome proliferator-activated receptors}

The PPARs are lipid-sensing and liporegulatory receptors (reviewed in Sugden \& Holness (2008)), and PPAR $\gamma$ is a key regulator in adipose tissue. Various ligands like eicosanoids and fatty acids activate this receptor, which forms permissive heterodimers with RXR, and controls genes involved in insulin signaling and glucose and fatty acid metabolism. Synthetic PPAR $\gamma$ agonists are in clinical use to improve glucose tolerance in diabetes mellitus. 
In 2006, organotins such as tributyltin chloride (TBT) were shown to be able to activate RXR and PPAR $\gamma$ by binding to the ligand binding domain of the receptors, thereby acting as agonists (Grun \& Blumberg 2006, Grun et al. 2006). Organotin compounds are chemicals composed of tin, directly bound to a number of organic groups. Organotins were first used in boat paint but their use is now restricted. The toxic effects of organotins in the aquatic environment include endocrine disturbances such as imposex in gastropods, namely development of male sexual characteristics in female mollusks. Human exposure to organotins occurs through fish and shellfish consumption (reviewed in Appel (2004)). Today, organotins are mostly used to protect wood and textiles from fungal growth and as stabilizers in plastic manufacturing.

Grün et al (2006) reported that the effects of RXR and PPAR $\gamma$ activation by TBT target the adipogenesis pathway. Specifically, TBT was shown to increase the number of differentiated adipocytes in the 3T3-L1 cell model and to disrupt normal adipogenesis in vertebrate developmental models. This raises the question of if chronic, low-dose organotin exposure, through diet and drinking water, could interfere with the control of adipogenesis, thereby promoting obesity.

Opposed to the obesogen hypothesis, it has been demonstrated in rodents and monkeys that exposure to perfluorinated compounds (PFCs), chemicals that have been found to increase in serum samples in the last years, have potent anorexigenic effects. PFCs, acting via PPAR $\alpha$, inhibit feeding behavior and weight gain (Butenhoff et al. 2002, Asakawa et al. 2008).

Interestingly, it has recently been shown that ER $\beta$ can act as a negative regulator of PPAR $\gamma$ (Foryst-Ludwig et al. 2008). It decreases ligand-induced PPAR $\gamma$ transcriptional activity and PPAR $\gamma$-induced adipogenesis in vitro. Additionally, ER $\beta$ knock-out mice show improved insulin response when kept on a high fat diet compared with wildtype mice. These findings suggest that PPAR $\gamma$ function cannot only be affected by EDCs directly interacting with the receptor, but also by EDCs that modulate ER $\beta$ activity.

\section{Conclusions}

Daily use of chemicals is an essential part of modern society. Yet with the exponentially increased production and release of synthetic chemicals, an unwanted effect includes introduction of toxic and persistent substances into the environment. Today, humans and wildlife are constantly exposed to thousands of chemical residues, through air, food, and water. However, scientific information regarding the long-term effects of this chronic, low-dose exposure to complex mixtures of chemicals is very limited. Furthermore, little is known about the quantities in which EDCs are taken up and stored in the body, and how these processes are affected by the carrier matrix such as type of food. Notably, food naturally contains various substances that act on the same receptors as EDCs, e.g., phytoestrogens. But, in contrast to EDCs, phytoestrogens have been shown in a number of studies to be beneficial for the organism, suggesting that activation of the same receptor can lead to distinct effects in the cell. This underlines the complexity of the mechanisms of action of EDCs, and demonstrates that we need to understand how the organism is affected by EDCs on a molecular level. Thus, additional research is required in order to identify and, if possible, quantify the risk that EDC exposure poses to human and wildlife populations. This information is necessary to establish relevant safety margins and to identify sensitive populations.

There is compelling evidence regarding the capacity of EDCs to interfere with the cellular signaling pathways such as those regulated by the NR family. The ability of certain chemicals, most notably dioxin, to interfere with estrogen signaling is well recognized. In addition to the regulation of reproductive system/function, estrogen activity is also an important regulator of other cellular processes including intermediate metabolism. Therefore, exposure to dioxins and other EDCs may not only increase reproductive problems but may also be an exacerbating factor in the development of other debilitating diseases such as metabolic syndrome.

In this review, we have summarized molecular mechanisms of endocrine disruption and evidence for the involvement of certain EDCs in the development of metabolic disease. The data show that there is indeed a potential risk that endocrine disruptors can induce human metabolic disorders, but they also illustrate that there is a lot more information needed to link molecular and toxicological/epidemiological information. The dramatic increase in obesity, in particular childhood obesity, shows that prevention and intervention actions are needed urgently. However, the complexity in the etiology of obesity and metabolic syndrome, in combination with the diversity of the endocrine systems involved, calls for more scientific information.

\section{Declaration of interest}

The authors declare that there is no conflict of interest that could be perceived as prejudicing the impartiality of the research reported.

\section{Funding}

The authors are supported by the European Commission funded CASCADE Network of Excellence (FOOD-CT-2003-506319), the European Commission funded CRESCENDO and PIONEER projects, the Swiss National Research Foundation (PA00A3-113129), the Magnus Bergvall Foundation and Academy of Finland. 


\section{References}

Alonso-Magdalena P, Ropero AB, Carrera MP, Cederroth CR, Baquie M, Gauthier BR, Nef S, Stefani E \& Nadal A 2008 Pancreatic insulin content regulation by the estrogen receptor ER alpha. PLoS ONE 3 e2069.

Appel KE 2004 Organotin compounds: toxicokinetic aspects. Drug Metabolism Reviews 36 763-786.

Arcaro KF, O'Keefe PW, Yang Y, Clayton W \& Gierthy JF 1999 Antiestrogenicity of environmental polycyclic aromatic hydrocarbons in human breast cancer cells. Toxicology 133 115-127.

Arsenescu V, Arsenescu RI, King V, Swanson H \& Cassis LA 2008 Polychlorinated biphenyl-77 induces adipocyte differentiation and proinflammatory adipokines and promotes obesity and atherosclerosis. Environmental Health Perspectives 116 761-768.

Asakawa A, Toyoshima M, Harada KH, Fujimiya M, Inoue K \& Koizumi A 2008 The ubiquitous environmental pollutant perfluorooctanoicacid inhibits feeding behavior via peroxisome proliferator-activated receptor-alpha. International Journal of Molecular Medicine 21 439-445.

Baillie-Hamilton PF 2002 Chemical toxins: a hypothesis to explain the global obesity epidemic. Journal of Alternative and Complementary Medicine 8 185-192.

Baker ME, Medlock KL \& Sheehan DM 1998 Flavonoids inhibit estrogen binding to rat alpha-fetoprotein. Proceedings of the Society for Experimental Biology and Medicine 217 317-321.

Boas M, Feldt-Rasmussen U, Skakkebaek NE \& Main KM 2006 Environmental chemicals and thyroid function. European Journal of Endocrinology 154 599-611.

Bonefeld-Jorgensen EC, Long M, Hofmeister MV \& Vinggaard AM 2007 Endocrine-disrupting potential of bisphenol A, bisphenol A dimethacrylate, 4-n-nonylphenol, and 4- $n$-octylphenol in vitro: new data and a brief review. Environmental Health Perspectives 115 69-76.

Brunnberg S, Pettersson K, Rydin E, Matthews J, Hanberg A \& Pongratz I 2003 The basic helix-loop-helix-PAS protein ARNT functions as a potent coactivator of estrogen receptor-dependent transcription. PNAS 100 6517-6522.

Butenhoff J, Costa G, Elcombe C, Farrar D, Hansen K, Iwai H, Jung R, Kennedy G Jr, Lieder P, Olsen G et al. 2002 Toxicity of ammonium perfluorooctanoate in male cynomolgus monkeys after oral dosing for 6 months. Toxicological Sciences 69 244-257.

Claessens F \& Gewirth DT 2004 DNA recognition by nuclear receptors. Essays in Biochemistry 40 59-72.

Colborn T 2004 Neurodevelopment and endocrine disruption. Environmental Health Perspectives 112 944-949.

Darnerud PO 2003 Toxic effects of brominated flame retardants in man and in wildlife. Environment International 29 841-853.

Darnerud PO 2008 Brominated flame retardants as possible endocrine disrupters. International Journal of Andrology 31 152-160.

Despres JP, Lemieux I, Bergeron J, Pibarot P, Mathieu P, Larose E, Rodes-Cabau J, Bertrand OF \& Poirier P 2008 Abdominal obesity and the metabolic syndrome: contribution to global cardiometabolic risk. Arteriosclerosis, Thrombosis, and Vascular Biology 28 1039-1049.

Elobeid MA \& Allison DB 2008 Putative environmental-endocrine disruptors and obesity: a review. Current Opinion in Endocrinology, Diabetes and Obesity 15 403-408.

Fierens S, Mairesse H, Heilier JF, De Burbure C, Focant JF, Eppe G, De Pauw E \& Bernard A 2003 Dioxin/polychlorinated biphenyl body burden, diabetes and endometriosis: findings in a populationbased study in Belgium. Biomarkers 8 529-534.

Foryst-Ludwig A, Clemenz M, Hohmann S, Hartge M, Sprang C, Frost N, Krikov M, Bhanot S, Barros R, Morani A et al. 2008 Metabolic actions of estrogen receptor beta (ERbeta) are mediated by a negative cross-talk with PPARgamma. PLoS Genetics 4 e1000108.
Gronemeyer H, Gustafsson JA \& Laudet V 2004 Principles for modulation of the nuclear receptor superfamily. Nature Review Drug Discovery 3 950-964.

Grun F \& Blumberg B 2006 Environmental obesogens: organotins and endocrine disruption via nuclear receptor signaling. Endocrinology 147 S50-S55.

Grun F, Watanabe H, Zamanian Z, Maeda L, Arima K, Cubacha R, Gardiner DM, Kanno J, Iguchi T \& Blumberg B 2006 Endocrinedisrupting organotin compounds are potent inducers of adipogenesis in vertebrates. Molecular Endocrinology 20 2141-2155.

Gunton JE, Kulkarni RN, Yim S, Okada T, Hawthorne WJ, Tseng YH, Roberson RS, Ricordi C, O'Connell PJ, Gonzalez FJ et al. 2005 Loss of ARNT/HIFlbeta mediates altered gene expression and pancreatic-islet dysfunction in human type 2 diabetes. Cell 122 337-349.

Hankinson O 2005 Role of coactivators in transcriptional activation by the aryl hydrocarbon receptor. Archives of Biochemistry and Biophysics 433 379-386.

Heine PA, Taylor JA, Iwamoto GA, Lubahn DB \& Cooke PS 2000 Increased adipose tissue in male and female estrogen receptoralpha knockout mice. PNAS 97 12729-12734.

Hockings JK, Thorne PA, Kemp MQ, Morgan SS, Selmin O \& Romagnolo DF 2006 The ligand status of the aromatic hydrocarbon receptor modulates transcriptional activation of BRCA-1 promoter by estrogen. Cancer Research 66 2224-2232.

Hoppe AA \& Carey GB 2007 Polybrominated diphenyl ethers as endocrine disruptors of adipocyte metabolism. Obesity 15 2942-2950.

Howdeshell KL, Peterman PH, Judy BM, Taylor JA, Orazio CE, Ruhlen RL \& Welshons WV 2003 Bisphenol A is released from used polycarbonate animal cages into water at room temperature. Environmental Health Perspectives 111 1180-1187.

Hugo ER 2008 Bisphenol A at environmentally relevant doses inhibits adiponectin release from human adipose tissue explants and adipocytes. Environmental Health Perspectives 116 1642-1647.

Janosek J, Hilscherova K, Blaha L \& Holoubek I 2006 Environmental xenobiotics and nuclear receptors-interactions, effects and in vitro assessment. Toxicology in Vitro 20 18-37.

Lang IA, Galloway TS, Scarlett A, Henley WE, Depledge M, Wallace RB \& Melzer D 2008 Association of urinary bisphenol A concentration with medical disorders and laboratory abnormalities in adults. JAMA 300 1303-1310.

Le HH, Carlson EM, Chua JP \& Belcher SM 2008 Bisphenol A is released from polycarbonate drinking bottles and mimics the neurotoxic actions of estrogen in developing cerebellar neurons. Toxicology Letters 176 149-156.

Lee JW, Lee YC, Na SY, Jung DJ \& Lee SK 2001 Transcriptional coregulators of the nuclear receptor superfamily: coactivators and corepressors. Cellular and Molecular Life Sciences 58 289-297.

Lee DH, Lee IK, Song K, Steffes M, Toscano W, Baker BA \& Jacobs DR Jr 2006 A strong dose-response relation between serum concentrations of persistent organic pollutants and diabetes: results from the National Health and Examination Survey 1999-2002. Diabetes Care 29 1638-1644.

Lee DH, Lee IK, Jin SH, Steffes M \& Jacobs DR Jr $2007 a$ Association between serum concentrations of persistent organic pollutants and insulin resistance among nondiabetic adults: results from the National Health and Nutrition Examination Survey 1999-2002. Diabetes Care 30 622-628.

Lee DH, Lee IK, Porta M, Steffes M \& Jacobs DR Jr $2007 b$ Relationship between serum concentrations of persistent organic pollutants and the prevalence of metabolic syndrome among non-diabetic adults: results from the National Health and Nutrition Examination Survey 1999-2002. Diabetologia 50 1841-1851.

Lee DH, Lee IK, Steffes M \& Jacobs DR Jr 2007c Extended analyses of the association between serum concentrations of persistent organic pollutants and diabetes. Diabetes Care 30 1596-1598. 
Lee MJ, Lin H, Liu CW, Wu MH, Liao WJ, Chang HH, Ku HC, Chien YS, Ding WH \& Kao YH 2008 Octylphenol stimulates resistin gene expression in 3T3-L1 adipocytes via the estrogen receptor and extracellular signal-regulated kinase pathways. American Journal of Physiology. Cell Physiology 294 C1542-C1551.

Legler J \& Brouwer A 2003 Are brominated flame retardants endocrine disruptors? Environment International 29 879-885.

Lim JS, Lee DH \& Jacobs DR Jr 2008 Association of brominated flame retardants with diabetes and metabolic syndrome in the US population: 2003-2004. Diabetes Care 31 1802-1807.

Martensson UE, Salehi SA, Windahl S, Gomez MF, Sward K, Daszkiewicz-Nilsson J, Wendt A, Andersson N, Hellstrand P, Grande PO et al. 2008 Deletion of the G protein-coupled receptor GPR30 impairs glucose tolerance, reduces bone growth, increases blood pressure, and eliminates estradiol-stimulated insulin release in female mice. Endocrinology 150 687-698.

Mattsson C \& Olsson T 2007 Estrogens and glucocorticoid hormones in adipose tissue metabolism. Current Medicinal Chemistry 14 2918-2924.

Meerts IA, Letcher RJ, Hoving S, Marsh G, Bergman A, Lemmen JG, van der Burg B \& Brouwer A 2001 In vitro estrogenicity of polybrominated diphenyl ethers, hydroxylated PDBEs, and polybrominated bisphenol A compounds. Environmental Health Perspectives 109 399-407.

Min G, Kim H, Bae Y, Petz L \& Kemper JK 2002 Inhibitory cross-talk between estrogen receptor (ER) and constitutively activated androstane receptor (CAR). CAR inhibits ER-mediated signaling pathway by squelching p160 coactivators. Journal of Biological Chemistry 277 34626-34633.

Newbold RR, Padilla-Banks E, Snyder RJ \& Jefferson WN $2007 a$ Perinatal exposure to environmental estrogens and the development of obesity. Molecular Nutrition and Food Research 51 912-917.

Newbold RR, Padilla-Banks E, Snyder RJ, Phillips TM \& Jefferson WN $2007 b$ Developmental exposure to endocrine disruptors and the obesity epidemic. Reproductive Toxicology 23 290-296.

Newbold RR, Padilla-Banks E, Jefferson WN \& Heindel JJ 2008 Effects of endocrine disruptors on obesity. International Journal of Andrology 31 201-208.

Ohtake F, Takeyama K, Matsumoto T, Kitagawa H, Yamamoto Y, Nohara K, Tohyama C, Krust A, Mimura J, Chambon P et al. 2003 Modulation of oestrogen receptor signalling by association with the activated dioxin receptor. Nature 423 545-550.

Ohtake F, Baba A, Takada I, Okada M, Iwasaki K, Miki H, Takahashi S, Kouzmenko A, Nohara K, Chiba T et al. 2007 Dioxin receptor is a ligand-dependent E3 ubiquitin ligase. Nature 446 562-566.

Oken E \& Gillman MW 2003 Fetal origins of obesity. Obesity Research 11 496-506.

Panzica GC, Viglietti-Panzica C \& Ottinger MA 2005 Introduction: neurobiological impact of environmental estrogens. Brain Research Bulletin 65 187-191.

Petrulis JR \& Perdew GH 2002 The role of chaperone proteins in the aryl hydrocarbon receptor core complex. Chemico-Biological Interactions 141 25-40.

Phillips LK \& Prins JB 2008 The link between abdominal obesity and the metabolic syndrome. Current Hypertension Reports 10 156-164.

Picard D 2006 Chaperoning steroid hormone action. Trends in Endocrinology and Metabolism 17 229-235.

Poland A \& Knutson JC2 1982 2,3,7,8-tetrachlorodibenzo-p-dioxin and related halogenated aromatic hydrocarbons: examination of the mechanism of toxicity. Annual Review of Pharmacology and Toxicology 22 517-554.

Prossnitz ER, Arterburn JB, Smith HO, Oprea TI, Sklar LA \& Hathaway HJ 2008 Estrogen signaling through the transmembrane G protein-coupled receptor GPR30. Annual Review of Pathology 70 165-190.
Reen RK, Cadwallader A \& Perdew GH 2002 The subdomains of the transactivation domain of the aryl hydrocarbon receptor (AhR) inhibit AhR and estrogen receptor transcriptional activity. Archives of Biochemistry and Biophysics 408 93-102.

Rüegg J, Swedenborg E, Wahlstrom D, Escande A, Balaguer P, Pettersson K \& Pongratz I 2007 The transcription factor ARNT functions as an estrogen receptor beta selective co-activator, and its recruitment to alternative pathways mediates anti-estrogenic effects of TCDD. Molecular Endocrinology 22 304-316.

Rüegg J, Penttinen-Damdimopoulou P, Mäkelä S, Pongratz I \& Gustafsson J 2008 Receptors mediating toxicity and their involvement in endocrine disruption. In Molecular, Clinical and Environmental Toxicology, pp 298-324. Ed A Luch. Basel: Birkhäuser Verlag AG.

Safe S \& Wormke M 2003 Inhibitory aryl hydrocarbon receptorestrogen receptor alpha cross-talk and mechanisms of action. Chemical Research in Toxicology 16 807-816.

Sato S, Shirakawa H, Tomita S, Ohsaki Y, Haketa K, Tooi O, Santo N, Tohkin M, Furukawa Y, Gonzalez FJ et al. 2008 Low-dose dioxins alter gene expression related to cholesterol biosynthesis, lipogenesis, and glucose metabolism through the aryl hydrocarbon receptor-mediated pathway in mouse liver. Toxicology and Applied Pharmacology 229 10-19.

Singleton DW \& Khan SA 2003 Xenoestrogen exposure and mechanisms of endocrine disruption. Frontiers in Bioscience $\mathbf{8}$ s110-s118.

Sugden MC \& Holness MJ 2008 Role of nuclear receptors in the modulation of insulin secretion in lipid-induced insulin resistance. Biochemical Society Transactions 36 891-900.

Swanson HI 2002 DNA binding and protein interactions of the AHR/ARNT heterodimer that facilitate gene activation. Chemico-Biological Interactions 141 63-76.

Swedenborg E, Rüegg J, Hillenweck A, Rehnmark S, Faulds MH, Zalko D, Pongratz I \& Pettersson K 2008 3-Methylcholanthrene displays dual effects on estrogen receptor (ER) alpha and ER beta signaling in a cell-type specific fashion. Molecular Pharmacology 73 575-586.

Tabb MM \& Blumberg B 2006 New modes of action for endocrinedisrupting chemicals. Molecular Endocrinology 20 475-482.

Takeda K, Toda K, Saibara T, Nakagawa M, Saika K, Onishi T, Sugiura T \& Shizuta Y 2003 Progressive development of insulin resistance phenotype in male mice with complete aromatase (CYP19) deficiency. Journal of Endocrinology 176 237-246.

Thackaberry EA, Bedrick EJ, Goens MB, Danielson L, Lund AK, Gabaldon D, Smith SM \& Walker MK 2003 Insulin regulation in AhR-null mice: embryonic cardiac enlargement, neonatal macrosomia, and altered insulin regulation and response in pregnant and aging AhR-null females. Toxicological Sciences 76 407-417.

Thomas P, Pang Y, Filardo EJ \& Dong J 2005 Identity of an estrogen membrane receptor coupled to a $\mathrm{G}$ protein in human breast cancer cells. Endocrinology 146 624-632.

Thomas P \& Dong J 2006 Binding and activation of the seven-transmembrane estrogen receptor GPR30 by environmental estrogens: a potential novel mechanism of endocrine disruption. Journal of Steroid Biochemistry and Molecular Biology 102 $175-179$.

Tsuchiya Y, Nakajima M \& Yokoi T 2005 Cytochrome P450-mediated metabolism of estrogens and its regulation in human. Cancer Letters 227 115-124.

Vandenberg LN, Hauser R, Marcus M, Olea N \& Welshons WV 2007 Human exposure to bisphenol A (BPA). Reproductive Toxicology 24 139-177.

Vidaeff AC \& Sever LE 2005 In utero exposure to environmental estrogens and male reproductive health: a systematic review of biological and epidemiologic evidence. Reproductive Toxicology 20 5-20. 
Wang X, Porter W, Krishnan V, Narasimhan TR \& Safe S 1993 Mechanism of 2,3,7,8-tetrachlorodibenzo-p-dioxin (TCDD)mediated decrease of the nuclear estrogen receptor in MCF-7 human breast cancer cells. Molecular Cellullar Endocrinology 96 159-166.

Watson G 2005. The Generations X report. WWF DetoX Campaign Welshons WV, Nagel SC \& vom Saal FS 2006 Large effects from small exposures, III. Endocrine mechanisms mediating effects of bisphenol A at levels of human exposure. Endocrinology 147 S56-S69.
Wu Y \& Koenig RJ 2000 Gene regulation by thyroid hormone. Trends in Endocrinology and Metabolism 11 207-211.

You L, Sar M, Bartolucci E, Ploch S \& Whitt M 2001 Induction of hepatic aromatase by $\mathrm{p}, \mathrm{p}^{\prime}$-DDE in adult male rats. Molecular Cellullar Endocrinology 178 207-214.

Received in final form 23 January 2009

Accepted 11 February 2009

Made available online as an Accepted Preprint 11 February 2009 